Irene Tourinho

Professora Titular da Faculdade de Artes Visuais da

Universidade Federal de Goiás, Doutora pela Universidade de Madison-Wisconsin.

\title{
EMOÇÕES E SENTIMENTOS: POLÊMICAS SOBRE O ENSINO DE ARTE
}

Avançar a concepção de ensino de arte, extrapolando a expressão de sentimentos e emoções

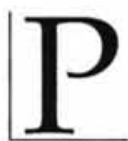

rofessores e professoras de arte sabem que a questão-título deste texto é comum. 'Ensinar arte como expressão de sentimentos e emoções' é um estereótipo que acompanha a profissão, mas ao mesmo tempo é uma idéia abrangente, rica e polêmica. Uma primeira evidência da abrangência desta idéia é a discussão em torno do próprio conceito de arte. Numa recente publicação de História da $\mathrm{Arte}^{1}$, vinte e três termos foram avaliados como pertinentes às questões da arte na contemporaneidade e cada um deles trata a arte a partir de diferentes abordagens. 'Fetiche', 'simulacro', 'contexto', 'representação', 'interpretação' e 'valor' são alguns dos termos discutidos neste livro e que demonstram a abrangência e riqueza da discus- são em que a arte e sua história são conceitos centrais.

Um dos editores ${ }^{2}$ da referida publicação chama a atenção para o fato de que "como artefato ou como objeto, a arte (...) retém uma aura e um determinado valor cultural, simbólico e especialmente econômico, e este valor está entrelaçado com sua história (...)". As conexões disciplinares e teóricas que participam da discussão sobre o conceito de arte são mais uma evidência da abrangência e riqueza que a idéia-título condensa: o status social, estético e até político da arte e seus objetos; o lugar ou condição de exibição; a posição do objeto dentro de um cânone artístico específico e o potencial ou a possibilidade de que o trabalho de arte possa transformar seu próprio ambiente ${ }^{3}$. Além

1. NELSON, Robert e SHIFF, Richard (Eds). Critical terms for Art History. (Termos críticos de História da Arte) Chicago: The University of Chicago Press, 1996.

2. NELSON. Robert. At the place of a foreword: someone looking, reading, and writing. In: NELSON, Robert $\mathrm{e}$ SHIFF, Richard (eds). Critical terms for Art History. (Termos críticos da História da Arte) Chicago: The University of Chicago Press, 1996. p.xiii.

3. NELSON, Robert. At the place ... op. cit. p.x. 
dessas, inter-relações mais comumente observadas e diretamente ligadas ao ensino de arte como expressão de sentimentos e emoções são: $\mathrm{o} e u$ do artista; $\mathrm{o} e u$ do objeto artístico e o $\mathrm{eu}$ do receptor ou apreciador.

A aura e o valor que a arte retém entre os seres humanos a coloca no foco de muitas polêmicas e, ao mesmo tempo, atesta sua fecundidade. Sabemos que aura e valor são histórica e culturalmente mutáveis. A teorização de Benjamim ${ }^{4}$ sobre a perda da aura da obra de arte significou uma abertura para pensar o conceito de aura a partir de novas contingências. Ao invés de perda, parece ter havido um deslocamento: o conceito de aura desprendeu-se da obra e deslocou-se para o 'contexto' no sentido amplo que Mondrian dá a este termo, citado em Mattick ${ }^{5}$. Para Mondrian, tudo deve ser visto como um complexo, como parte de um todo. Diz o artista, "nós sempre veremos relações e sempre saberemos uma coisa através de

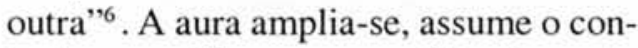
texto e ramifica-se com várias áreas do conhecimento, reforçando o valor da arte.

Podemos falar de valor da arte na nossa cultura e sociedade - ou nos grupos que as constituem - e de valor da arte como resultado de uma avaliação sobre um objeto/manifestação artística. Em ambos os casos, a tarefa fundamental da arte, desde o Iluminismo, tem sido a de "submeter todos os valores absolutos ao julgamento crítico" ". Mesmo sem os valores absolutos que definiriam qual arte seria a verdadeira, a certa ou a bela, as investigações sobre o valor da arte não foram abandonadas. Ficam sempre muitas perguntas: como são criados os consensos a respeito de certos trabalhos de arte? Como certas interpretações se tornam legitimadas? Como a família e a escola colaboram para - ou prejudicam - a formação do interesse pela arte? O que diferencia um objeto artístico de outros objetos? Que tipos de manifestações podem ser considerados artísticos?

As relações da arte com outras disciplinas, como a História, a Antropologia e a Psicanálise, acrescentaram novos tópicos à discussão sobre arte e reiteraram a importância da arte para a vida pessoal e social dos indivíduos.

Exemplos de questões advindas das relações da arte com estas disciplinas são: em que medida a História da Arte interpreta o presente com base no passado e em que medida ela deveria ter o futuro como perspectiva para interpretar o presente? Como o fazer arte se distingue de outras atividades diárias, cotidianas? Que contribuições a experiência estética oferece para a formação dos indivíduos?

Como campo de conhecimento, a arte manterá mistérios e segredos que continuarão a nos incitar. A Estética é uma disciplina nova, se comparada com

4. BENJAMIM, W. The work of art in the age of mechanical reproduction. (A obra de arte na era da reprodução técnica.) In: ARENDT, Hannah (ed.) Illuminations. [s.I.] [s.n.] 1968.

5. MATTICK, P. Context.(Contexto) In: NELSON, Robert e SHIFF, Richard (eds). Critical terms for Art History. Chicago: The University of Chicago Press, 1996. p.70-86.

6. MATTICK, P. Context.(Contexto) ... op. cit.

7. KOERNER, J. e KOERNER, L. Value. (Valor) In: NELSON, Robert e SHIFF, Richard (eds) ... op. cit. p. 293. 
a Filosofia. Esta disciplina nem sempre tem seu território nitidamente demarcado já que uma nasce da outra. Mas é só no século XVIII, ainda atrelada à Filosofia, que a preocupação com a arte como morada privilegiada da beleza aparece e é apenas no seguinte, século XIX, que o artista ganha status de um indivíduo especial, dotado de grande personalidade, visto como se fosse um profeta ou um líder. É, portanto, no século XIX que as preocupações com a emoção e os sentimentos do artista predominam nas discussões sobre arte.

Fica claro que o tema - arte como expressão de sentimentos e emoções - é abrangente e rico, mesmo se considerarmos apenas seu primeiro conceito, ou seja, arte. Discutirei alguns riscos deste tema, primeiro, em relação a outras possibilidades da arte como, por exemplo, a de que ela expresse valores e comportamentos. Discuto, ainda, alguns riscos que surgem da associação do conceito de 'arte' aos de 'expressão', 'emoção' e 'sentimento'. Por último, penso o tema-título em relação ao ensino de arte, propondo algumas idéiasguia que possam contribuir para o trabalho que pretendemos desenvolver com docentes. Meu objetivo é iniciar um debate que espero acontecer a partir da apresentação dessas idéias.

\section{RISCOS E POLÊMICAS DA IDÉIA DE ARTE COMO EXPRESSÃO}

Um dos maiores riscos deste tema talvez seja o de privilegiar uma dimensão da arte em detrimento de tantas outras possí- veis. Quando dizemos que a 'arte expressa', associamos esta idéia a algum tipo de conteúdo ${ }^{8}$. Aprisionar este conteúdo-que é denso, ambíguo e múltiplo - na esfera do sentimento e da emoção é reduzir as possibilidades da arte. Mesmo pensando a expressão como um conceito amplo, guardachuva, é necessário pensar a distinção entre 'expressar uma emoção' e 'incitar ou provocar' uma emoção. É necessário, ainda, distinguir a 'expressão' como uma ação ou estado do artista e a 'expressão' enquanto 'expressividade' de uma obra.

Assim como é arriscado dizer que uma obra de arte possa ser destituída de expressividade, também é um risco dizer que os sentimentos e as emoções são necessariamente o foco desta expressividade.

Hospers ${ }^{9}$ discute essas distinções e especificidades da 'expressão', registrando o fato de que é na modernidade que a teoria da arte como expressão domina a cena estética. Hospers atenta, então, para a historicidade do conceito de 'expressão', lembrando-nos que os "artistas criaram grandes trabalhos de arte durante muitos séculos e apenas nos últimos dois séculos ou menos se tornou costume, ou até natural, dizer que a atividade distintiva do ar-

8. SOUCY, D. Não existe expressão sem contetido. In: BARBOSA. Ana Mae e SALLES, Heloisa (orgs.) O ensino da arte e sua história. Sâo Paulo: Museu de Arte Contemporânea/USP, 1990. p.87-95.

9. HOSPERS, J. The concept of artistic expression. (O conceito de expressão artística) In: WEITZ, Morris. Problems in aesthetics. (Problemas de estética) New York: Macmillan, 1989. p. 221-245. 
tista é a expressão"10 . Segundo Hospers, a idéia de expressão como uma descrição geral da atividade artística é estreita e "reflete uma reminiscência do conceito místico de gênio, fomentado na era romântica"" .

Além da redução que a idéia de 'arte como expressão' representa, atrelar esta idéia apenas aos sentimentos e emoções é reduzir ainda mais o âmbito possível da discussão sobre arte e expressão.

O risco é pensar, primeiro, na arte apenas como expressão; e, segundo, na expressão como um canal de exteriorização apenas de sentimentos e emoções.

'Denunciar', 'negar', 'representar' e 'explicitar' são conceitos que, ao lado de 'expressão', também podem descrever a atividade artística. Citei anteriormente a idéia de arte como expressão de valores e comportamentos e penso em Tolstoy como um exemplo clássico de defesa da primeira idéia. Na visão do escritor russo, os sentimentos e as emoções são centrais, mas devem servir a um valor maior que é o da união espiritual e satisfatória entre os povos. Tolstoy afirmava que "a atividade da arte está baseada no fato de que um homem, recebendo através da audição ou visão a expressão de sentimentos de outro homem, seja capaz de experimentar a emoção que moveu o homem que a expressou"12.

O sujeito-artista e sua capacidade de expressão, de um lado, e o sujeito-espectador e sua capacidade de percepção dessa expressão, de outro, formam a base da idéia de arte no pensamento de Tolstoy. Mas, para ele, não é suficiente que os espectadores percebam e sejam "infectados pelos sentimentos que o autor sentiu"13. O valor maior da arte aquilo que a define e a distingue de outras atividades - é ser um meio de unir todos os homens nos mesmos sentimentos "indispensáveis para a vida e progresso em direção ao bem-estar de indivíduos e da humanidade" ${ }^{14}$. No caso de Tolstoy, são os valores que os sentimentos evocam e não os sentimentos per $s e$, que atestam sobre a arte. E só é arte aquilo que satisfaz esta condição.

As posições de Tolstoy e Hosper são claramente distintas e historicamente distantes. Dificilmente a posição de Tolstoy encontraria adeptos na reflexão estética contemporânea. Enquanto ele elege e congela os sentimentos do artista para ser captado e experimentado pelo espectador com vistas a um mundo meIhor, Hospers questiona a própria existência de sentimentos específicos ou nomeáveis para que algo seja considerado arte. Para Hospers, as especulações sobre os sentimentos do artista não dizem respeito à qualidade da obra e nem ao poder que ela possa ter para condensar e caracterizar certos sentimentos que são 
humanamente reconhecíveis e compreensíveis. Expressar valores humanitários através da evocação de sentimentos é, portanto, uma das possibilidades da arte, mas arte não expressa só isso e nem esta forma de expressão é monopólio das artes.

Exemplos de arte como expressão de comportamentos ou situações também são abundantes. Penso nos registros épi$\cos$, históricos e sociais que a arte oferece e onde o ser humano pode ser visto nas mais contrastantes circunstâncias que vão da guerra à paixão, da solidariedade à exploração. A arte também explicita ou nos coloca diante de certos comportamentos evocando e provocando pensamentos que podem, ou não, desembocar em sentimentos. Há uma região incerta onde pensamento e sentimento se misturam, se complementam e se reforçam sem que nenhum se sobreponha ao outro. Goodmam $^{15}$ tem razão ao observar que nas artes, ou melhor, na experiência estética, as emoções funcionam cognitivamente. Certamente que a prática docente em arte tem seus próprios exemplos sobre como os valores que a arte expressa podem ter uma função educacional e socializante - da motivação para certas atividades, das trocas pessoais, da adesão ou estranhamento sobre realidades e práticas.

A ênfase romântica sobre o indivíduo fez com que a arte fosse entendida quase que exclusivamente através deste viés: expressar emoções e sentimentos. Sem a radicalidade da 'transmissão' e 'experimentação' de sentimentos que Tolstoy pro- jeta na relação artista-espectador, a idéia de arte como expressão de sentimentos e emoções é senso-comum e muitos alunos(as) e professores(as) ainda se mantêm afeiçoados a ela. Entretanto, a estética contemporânea, diferentemente da estética moderna, não dissocia o objeto artístico das circunstâncias de sua produção e consumo.

Não apenas as circunstâncias materiais, mas também as sociais, culturais e históricas devem ser consideradas. Pensar a arte unicamente como expressão de sentimentos e emoções resulta ou na supervalorização do artista ou do objeto.

Fica esvaziada a participação de outros componentes no processo artístico como, por exemplo, o público, o contexto, as experiências e as condições de produção, exibição e percepção. Seria o caso, então, de perguntarmos: a idéia da arte como expressão de emoções e sentimentos privilegia quais aspectos da nossa relação com a arte? Deixa quais aspectos de fora: conteúdo? contexto? cultura?

Reforço o fato de que os riscos da idéia de arte como expressão não se restringem a pensar apenas sobre o quê a arte pode expressar. Estes riscos atingem também a idéia de que a arte, além

15. GOODMAN, N. Of mind and other matters. (Sobre a mente e outras matérias) Cambridge, Mass: Harvard University Press, 1984. 
de expressar - sentimentos, emoções, valores ou atitudes - pode construir, provocar e gerar conhecimento. A 'expressão', portanto, não se separa de um 'conteúdo' e de uma 'forma' e tanto uma coisa quanto outra se articulam num determinado contexto de uma dada cultura e num espaço histórico definido. É por esta razão que a idéia de arte como expressão de sentimentos e emoção precisa ser repensada para atender as contingências e diversidades que caracterizam as situações em que a arte 'opera', com suas inúmeras possibilidades.

A importância daquilo que o tema deixa escapar ou que não explicita, em termos da arte, é uma polêmica que exige reflexão e crítica constante. Todavia, a consciência de que a expressão de sentimentos e emoções é uma redução sobre o que a arte pode fazer, não nos isenta de indagações que são decorrentes desta posição. Essas indagações orientam o restante deste trabalho.

\section{SENTIMENTOS E EMOÇÕES: PERCALÇOS E PERCURSOS}

No início do trabalho citei uma publicação que discute vinte e três termos considerados pertinentes para a reflexão sobre a arte na contemporaneidade. Nenhum dos termos deste tema - expressão, sentimento e emoção - aparece naquela seleção. Num certo sentido, a pós-modernidade destituiu o poder que estes termos tiveram durante a modernidade, quando então se defendia a capacidade do indivíduo para expressar "aquilo que é mais subjetivo dentro do sujeito"16.

A pós-modernidade complica e implode esta situação. Complica na medida em que libera a arte - sem eliminardas amarras do sentimento, da emoção e da própria expressão. Liberando-se destas amarras, a arte cumpre sua tarefa de criticar quaisquer valores absolutos, recusando-se a ser propriedade exclusiva seja dos sentimentos, das emoções ou das idéias.

A pós-modernidade implode a idéia de 'arte como expressão' porque expande o campo da arte tanto em termos temáticos quanto interpretativos.

Historicamente, a idéia da arte como expressão de emoções e sentimentos representou uma mudança em relação à idéia de arte como imitação da natureza. Mas nenhuma dessas idéias respondeu à crescente diversificação da produção e conseqüente expansão do campo da arte. Reitera-se, em todo momento, a função crítica e questionadora que a arte e suas práticas exercem nas sociedades. Para o filósofo norte-americano Arthur Danto, esta mudança do olho (imitação) para a psique (expressão), no modernismo, "trouxe para o debate um número de fatores que não teriam relevância especial anteriormente" ${ }^{17}$. Um exemplo que o autor cita é o da 'sinceridade' do artista: se a

16. KOERNER, J. e KOERNER, L. Value. (Valor) In: NELSON, Robert e SHIFF, Richard (eds). Critical ... op. cit. p. 302.

17. DANTO, A. After the end of Art - Contemporary Art and the pale of History. (Depois do fim da arte - A arte contemporânea e o empalidecer da História) Princeton: Princeton University Press, 1997. p. 65. 
arte sempre expressa emoções e sentimentos, como o conceito de 'sinceridade' deve entrar em nossos debates?

Vimos alguns riscos e polêmicas da idéia de arte como expressão. Emoção e sentimento são conceitos historicamente situados, assim como qualquer outro conceito. Em alguns dicionários, 'emoção' ainda é definida como reação intensa, perturbada e descontrolada de um indivíduo frente a algo inesperado ou grandioso. Até recentemente, 'emoção' era um conceito entendido como desordem psicológica e psíquica. Pessoas que tornavam público suas emoções eram consideradas fracas, intelectualmente deficientes e incapazes para tratar as coisas de maneira objetiva.

\section{A compreensão que se tem} desses termos é importante porque ela orienta a visão que construímos sobre a experiência de criação, percepção e julgamento da arte.

No livro Sentimento e razão nas artes, David Best ${ }^{18}$ afirma haver, primeiro, uma confusão entre a emoção e o comportamento que a expressa (emoção). Essa confusão, segundo ele, desconsidera a possibilidade de que existam emoções que não possam ser expressas.
Outra confusão é entender emoção como sensação. Best diz que "esta tentação é reforçada pelo fato de que (a) quando a expressão é suprimida, as sensações tendem a manter-se, e (b) as emoções intensas (...) são caracterizadas por sensações e mudanças físicas tais como a aceleração do pulso, empalidecimento, transpiração e ruborização" 19 . O fato é que emoção, sentimento e sensação não são sinônimas e, conforme observa Best, suas diferenças podem orientar, de maneira especial, aos arte-educadores.

Uma característica da emoção que a distingue da sensação, segundo Best, "é que na grande maioria dos casos [as emoções] são direcionadas para um objeto". Best explica que "o objeto, neste sentido, não é necessariamente um objeto físico" ${ }^{20}$, mas tudo o que é perceptível ou apreensível. Sempre há um objeto, ou seja: um indivíduo está triste em consequiência de alguma coisa; ansioso em relação a algo ou irritado com algo. A presença do objeto como característica da emoção estabelece um primeiro tipo de relação: a do indivíduo (consciência) com o objeto. Mas a emoção tem seu próprio mundo - alegre, horrível, cruel, fantástico - e este mundo cria outra relação, também primordial, que é justamente a do indivíduo com o mundo.

Sartre, no livro As emoções - esboço de uma teoria, fala do mundo das emoções e escreve que "a emoção é a transformação do mundo" "21. A teoria das emoções que Sartre delineia nesta obra é

18. BEST. D. Feeling and reason in the arts. (Sentimento e razão nas artes) Boston: George Allen \& Unwin Publishers. 1985 .

19. BEST, D. Feeling and... op. cit. p. 91.

20. BEST, D. Feeling and... op. cit. p. 93.

21. SARTRE, J. P. The emotions... op. cit. 
fenomenológica e, nesta linha, apesar de Sartre não se referir especificamente à arte, a transformação tem um caráter que envolve tanto o sujeito e a obra quanto o contexto onde se dá a relação indivíduoarte. A ênfase na transformação - do sujeito, da arte, do contexto e das formas de relação com a arte - é um fator preponderante para pensar o papel da emoção e dos sentimentos nos processos educacionais.

Se todo processo educativo está entrelaçado com algum tipo de transformação do sujeito e de sua forma de perceber o mundo, no ensino de arte as emoções e os sentimentos participam deste mesmo processo.

Goodmam é claro quando diz que o sentimento e a emoção iniciais diante de um trabalho de arte "pode levar-nos a examiná-lo mais longamente e a compreendê-lo melhor e esta melhor compreensão e o processo de adquiri-la pode oferecer uma nova e maior satisfação" 22 . O comentário de Goodmam enfatiza o processo e principalmente, a possibilidade e necessidade de que emoções e sentimentos se transformem neste processo.

Processos educativos são sempre marcados por contingências de ordem intra e extra-institucional. A consciência de que sentimentos e emoções participam do en- sino de arte e de que, neste processo, devem ser transformados, pede uma contínua reflexão sobre a questão-título deste texto. Educar para a transformação exige uma revisão da idéia de 'arte como expressão de sentimentos e emoções'. Para orientar esta revisão, entendemos ser preciso pensar que sentimentos e emoções são:

(1) construídos socialmente e historicamente contextualizados. Emoções e sentimentos se referem a algo, ou a alguém, que está no mundo. Isso significa que emoções e sentimentos existem na medida em que tomamos consciência deles e esta consciência é formada a partir das contingências sociais e históricas em que tais sentimentos e emoções acontecem;

(2) focos parciais para a apreciação e análise da arte e da experiência artística. Emoções e sentimentos participam, mas não definem, não esgotam e nem são necessariamente o foco principal do processo de compreensão artística. Isso significa que a expressão mescla-se com um todo, ou seja, com indivíduos (artistas e apreciadores) $\mathrm{em}$ relação, num determinado tempo/contexto onde emoções e sentimentos são construídos;

(3) mutáveis e culturalmente diversificados. Emoções e sentimentos são produtos de relações entre indivíduos e sua cultura. São, ainda, produtos das relações que os indivíduos estabelecem entre culturas. Isso significa que os trabalhos de arte não carregam apenas as histórias pessoais de um artista, mas uma dinâmica de relações entre artistas, indivíduos, arte, cultura e história. 
As idéias de processo/aprendizagem, ensino e experiência sustentam estas noções e orientam uma revisão da idéia de 'arte como expressão de sentimentos e emoções'. Como objetos de reflexão, emoções e sentimentos podem ser elaborados, aprofundados e refinados para enfatizar transformações que, especial-

Resumo: $\mathrm{O}$ artigo discute a idéia de arte como 'expressão de sentimentos e emoçōes', partindo da constatação de que ela ainda é comum, quase um estereótipo, entre professores e professoras de arte. Os termos dessa idéia (arte - expressão - sentimento - emoção) são focos de uma reflexão que aponta alguns riscos da noção de arte como expressão e, principalmente, de arte como expressão de sentimentos e emoçōes. Sem negar a expressividade $\mathrm{da} / \mathrm{na}$ arte ou as possibilidades de que emoções e sentimentos possam estar 'expressos' na arte, o artigo chama a atenção para a parcialidade, mutabilidade, contextualidade e historicidade da idéia em questão. Estes pontos são sugeridos como importantes para revisar a idéia de 'arte como expressão de sentimentos e emoções', relativizando e redimensionando sua função no ensino de arte.

Palavras-chave: ensino, arte, expressão, sentimento, emoção, arte-educação mente após a década de 60 , apontaram para o que Mattick" ${ }^{23}$ chama de "dessantificação" da arte e para uma decisiva consideração sobre suas conexões com o restante da vida cultural, econômica e social. Os mitos de um "olhar inocente" ou de uma "emoção sem mente", conforme observa Goodmam, tornaram-se obsoletos.

(Emotions and feelings: controversy on teaching art)

Abstract. The article discusses the idea of art as the 'expression of feelings and emotions,' beginning from the contestation of the idea that it is still common, nearly a stereotype, among professors of art. The terms of this idea (art expression - feelings - emotion) are the focus of a reflection that points to a few risks in the notion of art as expression and, most especially, of art as the expression of feelings and emotions. Without denying the expressiveness of/in art, or the possibility that emotions and feelings may be 'expressed' in art, the article calls one's attention to the partiality, mutability, contextuality and historicity of the idea in question. These points are suggested as important to review the idea of 'art as the expression of feelings and emotions,' making its function relative and redimensioning its role in teaching art.

Key words: teaching, art, expression, feelings, emotion, art-education 